\section{Der p 23: Clinical Relevance of Molecular Monosensitization in House Dust Mite Allergy}

Matos Semedo $\mathrm{F}^{1,3}$, Dorofeeva $\mathrm{Y}^{2}$, Pires AP ${ }^{1}$, Tomaz E $\mathrm{E}^{1}$, Taborda Barata $\mathrm{L}^{3,4}$, Inácio $\mathrm{F}^{1}$, Valenta $\mathrm{R}^{2}$

${ }^{1}$ Allergy and Immunology Department, São Bernardo Hospital, Centro Hospitalar de Setúbal E.P.E., Setúbal, Portugal

${ }^{2}$ Center for Pathophysiology, Infectiology and Immunology, Department. of Pathophysiology and Allergy Research/Division of Immunopathology, Medical University of Vienna, Vienna, Austria ${ }^{3}$ CICS - Health Sciences Research Centre, Faculty of Health Sciences, University of Beira Interior, Covilhã, Portugal ${ }^{4}$ Department of Allergy \& Clinical Immunology, Cova da Beira University Hospital, Covilhã, Portugal

J Investig Allergol Clin Immunol 2019; Vol. 29(4): 314-316 doi: $10.18176 /$ jiaci.0392

Key words: Dermatophagoides pteronyssinus. Allergens. Asthma. Rhinitis.

Palabras clave: Dermatophagoides pteronyssinus. Alérgenos. Asma. Rinitis.

House dust mite (HDM) allergy affects approximately $2 \%$ of the world's population, thus generating a major health care and economic burden [1]. Component-resolved diagnostics provides greater diagnostic accuracy and enables better patient management [2].

Specific immunotherapy (SIT) is an effective approach in sensitized individuals with allergic respiratory disease. However, in comparison with SIT for grass or birch pollen, SIT for HDM allergy is significantly less successful [3]. This reduced efficacy might be explained by poor standardization of most commercially available HDM extracts. Variable amounts of the main HDM allergens (Der p 1, Der p 2, Der p 23) and even absence of important components in the different commercial extracts may underlie insufficient therapeutic outcomes in some groups of HDM-allergic patients [4].

Der $\mathrm{p}$ 23, a peritrophin-like protein, was recently identified as a new major allergen of Dermatophagoides pteronyssinus [5]. It is recognized by approximately $75 \%$ of patients and has been shown to induce IgE-dependent basophil activation, thus indicating high allergenic activity. A recent study based on the sera of 722 participants from the German Multicenter Allergy Study showed that IgE to Der p 23 at 5 years of age or less was predictive of asthma at school age [6]. Nevertheless, data concerning the clinical relevance of Der $\mathrm{p} 23$ are still lacking. The recent commercial availability of the allergen for diagnostics allowed us to identify a new group of patients sensitized only to Der p 23 and not to other major HDM allergens. Thus, the aim of the present study was to analyze the relationship between sensitization to Der $\mathrm{p} 23$ and clinical symptoms of allergic diseases in sensitized patients.

Patient data were selected from the database of the Department of Allergy and Immunology of Hospital de São Bernardo, Centro Hospitalar de Setúbal E.P.E., Setúbal, Portugal. The study was approved by the local ethics committee and the national data protection commission. The database was scanned for patients with perennial allergy to HDM who were referred to our institution between 2010 and 2018. Patient selection was based on the following criteria: (1) history of perennial allergic symptoms; (2) positive skin prick test to $D$ pteronyssinus (wheal $\geq 3 \mathrm{~mm}$ ); (3) specific IgE to total extract of $D$ pteronyssinus $\geq 0.35 \mathrm{kU}_{\mathrm{A}} / \mathrm{L}$ (ImmunoCAP, Thermo Fisher Scientific); and (4) specific IgE to Der $p 1$ and Der p $2 \leq 0.35 \mathrm{kU}_{\mathrm{A}} / \mathrm{L}$ and to Der p $23 \geq 0.35 \mathrm{kU}_{\mathrm{A}} / \mathrm{L}$ (ImmunoCAP, Thermo Fisher Scientific). All patients were analyzed in May 2017 using frozen sera stored in our biobank.

Patients' sera were transferred to the Department of Pathophysiology and Allergy Research, Medical University of Vienna, Austria for MeDALL chip analysis [7], which is based on microarray technology for diagnosis and monitoring of IgE and $\operatorname{IgG}$ reactivity profiles for a wide range of allergens. The chip contains a panel of 13 components of $D$ pteronyssinus (Der p 1, Der p 2, Der p 4, Der p 5, Der p 7, Der p 10, Der p 11,

Table. Detailed Evaluation of the 7 House Dust Mite-Allergic Patients Who Were Negative for Der $p 1$ And Der $p 2$ and Positive for Der p 23 by Conventional IgE Serology (ImmunoCAP)

\begin{tabular}{|c|c|c|c|c|c|c|c|c|}
\hline $\begin{array}{l}\text { Patient } \\
\text { No. }\end{array}$ & Sex & $\begin{array}{l}\text { Age, } \\
\text { y }\end{array}$ & $\begin{array}{c}\text { Respiratory } \\
\text { Allergy }\end{array}$ & $\begin{array}{c}\mathrm{sIgE} \\
\text { D pter, } \\
\mathrm{kU}_{\mathrm{A}} / \mathrm{L}\end{array}$ & $\begin{array}{c}\operatorname{sIgE} \\
\operatorname{Der} p 23 \\
\mathrm{kU}_{\mathrm{A}} / \mathrm{L}\end{array}$ & $\begin{array}{l}\text { MeDALL } \\
\text { Der p 23, }\end{array}$ & $\begin{array}{c}\text { MeDALL } \\
\text { Other Components } \\
\text { of } D \text { pter }\end{array}$ & $\begin{array}{c}\text { MeDALL } \\
\text { Other Perennial } \\
\text { Sensitizations }\end{array}$ \\
\hline 1 & $\mathrm{M}$ & 26 & Rhinitis & 1.74 & 4.16 & 7.11 & Negative & Can $\mathrm{f} 5$ \\
\hline 2 & $\mathrm{~F}$ & 43 & Rhinitis & 0.98 & 1.02 & 1.75 & Negative & - \\
\hline 3 & $\mathrm{M}$ & 7 & Rhinitis + asthma & 31.0 & 15.7 & 16.7 & $\begin{array}{c}\text { Der } \mathrm{p} 5, \text { Der } \mathrm{p} 7 \\
\text { Der } \mathrm{p} 18\end{array}$ & $\begin{array}{l}\text { Fel d 1, Fel d 2, } \\
\text { Lep d } 2\end{array}$ \\
\hline 4 & $\mathrm{M}$ & 10 & Rhinitis & 4.22 & 5.54 & 0.65 & Negative & - \\
\hline 5 & M & 13 & Rhinitis & 2.02 & 4.43 & 3.65 & Negative & - \\
\hline 6 & $\mathrm{M}$ & 36 & Rhinitis + asthma & 18.5 & 4.55 & 0.97 & Negative & Can f 5, Lep d 2 \\
\hline 7 & $\mathrm{~F}$ & 35 & Rhinitis + asthma & 22.6 & 30.9 & 17.9 & Negative & - \\
\hline
\end{tabular}

Abbreviations: D pter, Dermatophagoides pteronyssinus; - = none 
Der p 14, Der p 15, Der p 18, Der p 21, Der p 23, and clone 16-encoded allergen).

From the initial database of 144 HDM-allergic patients with measured levels of IgE specific to $D$ pteronyssinus and to Der $\mathrm{p} \mathrm{1,} \mathrm{Der} \mathrm{p} \mathrm{2,} \mathrm{and} \mathrm{Der} \mathrm{p} \mathrm{23,} 7$ patients (4.9\%) met the abovementioned criteria and were analyzed using the MeDALL chip (Table). All 7 patients had symptoms of perennial rhinitis, and 3 also had asthma, although none of the patients had ever received SIT.

Six of the 7 patients were sensitized only to Der p 23 and to no other HDM allergens on the chip.

Regarding other types of perennial sensitization, none of the tested sera showed IgE reactivity to major allergen components of Dermatophagoides farinae (Der f 1 and Der f 2), although 3 patients were sensitized to pet allergens, and 2 of those patients were also sensitized to Lepidoglyphus destructor (Lep d 2) (Table).

The importance of Der $\mathrm{p} 23$ as a new major HDM allergen is supported by numerous research groups [8]. However, few data have been published concerning monosensitization to this new major allergen. In 2016, Becker at al [9] described a similar group of $5 \mathrm{HDM}$-allergic patients tested with the MeDALL chip; the results were positive for Der p 23 in all 5 cases, whereas findings for other HDM allergen components were negative. Thus, from a molecular point of view, those patients were regarded as being truly monosensitized to this allergen.

According to studies on the prevalence of $\mathrm{IgE}$ recognition and allergen-specific IgE levels, Der p 1, 2, 5, 7, 21, and 23 appear to be the most clinically relevant HDM allergens and are all represented on the MeDALL chip, alongside other allergens. However, despite the comprehensive panel of molecular components, the possibility still remains that these patients might have IgE reactivity to other HDM allergens not represented on the chip [10].

Our results showed that 3 patients were also sensitized to pet allergens. Two of these pet-allergic patients were sensitized to $L$ destructor, an important storage mite in the Mediterranean area. Therefore, we cannot exclude the possibility that $\operatorname{IgE}$ reactivity to both of these groups of allergens might be a cause of perennial rhinitis and asthma. However, the remaining 4 patients had clinical symptoms of respiratory allergy that were most probably due to sensitization to Der $\mathrm{p}$ 23, thereby highlighting the clinical relevance of this allergen. This is important, since, in a study carried out in 384 HDMallergic individuals in Spain [11], various HDM molecular compositions were shown to be differentially associated with asthma in sensitized adults.

Our results regarding Der $\mathrm{p} 23$ are interesting but should be interpreted with caution. Firstly, monosensitization to Der p 23 seems to be a rare event. Secondly, our sample size is small. Thirdly, relationships between serum levels of specific HDM allergens and clinical relevance as detected by target-organ provocation tests is not always clear [12]. Nevertheless, although Der p 23 is only present in low amounts in house dust and also in HDM extracts, it has previously been shown to induce high IgE titers [13]. In addition, the presence of clinical symptoms of HDM allergy in the present group of Der $\mathrm{p} 23-$ monosensitized patients suggests that this allergen itself is clinically relevant. Although more studies are warranted to further clarify the clinical relevance of Der p 23, our results suggest that sensitization to this allergen should be borne in mind when using HDM extract.

\section{Funding}

The authors declare that no funding was received for the present study.

\section{Conflicts of Interest}

The authors declare that they have no conflicts of interest.

\section{References}

1. Taketomi EA, Silva DA, Sopelete MC, Gervásio AM, Alves $\mathrm{R}$, Sung SJ. Differential IgE reactivity to Der $p 1$ and Der $p$ 2 allergens of Dermatophagoides pteronyssinus in mitesensitized patients. J Investig Allergol Clin Immunol. 2006;16:104-9.

2. Valenta $R$, Lidholm J, Niederberger $V$, Hayek B, Kraft $D$, Grönlund $H$. The recombinant allergen-based concept of component-resolved diagnostics and immunotherapy (CRD and CRIT). Clin Exp Allergy. 1999;29:896-904. Doi: 10.1046/j.1365-2222.1999.00653.x.

3. Nelson HS. Update on house dust mite immunotherapy: are more studies needed? Curr Opin Allergy Clin Immunol. 2014;14:542-8. Doi: 10.1097/ACI. 0000000000000104.

4. Calderon MA, Casale TB, Nelson HS, Demoly P. An evidencebased analysis of house dust mite allergen immunotherapy: a call for more rigorous clinical studies. J Allergy Clin Immunol. 2013;132:1322-36. Doi: 10.1016/j.jaci.2013.09.004.

5. Weghofer $M$, Grote $M$, Resch $Y$, Casset $A$, Kneidinger $M$, Kopec J, et al. Identification of Der p 23, a peritrophin-like protein, as a new major Dermatophagoides pteronyssinus allergen associated with the peritrophic matrix of mite fecal pellets. J Immunol. 2013;190:3059-67. Doi: 10.4049/ jimmunol. 1202288.

6. Posa D, Perna S, Resch Y, Lupinek C, Panetta V, Hofmaier S, et al. Evolution and predictive value of IgE responses toward a comprehensive panel of house dust mite allergens during the first 2 decades of life. J Allergy Clin Immunol. 2017;139:5419. Doi: 10.1016/j.jaci.2016.08.014.

7. Lupinek C, Wollmann E, Baar A, Banerjee S, Breiteneder $\mathrm{H}$, Broecker BM, et al. Advances in allergen-microarray technology for diagnosis and monitoring of allergy: the MeDALL allergen-chip. Methods. 2014;66:106-19. Doi: 10.1016/j.ymeth.2013.10.008

8. Batard T, Baron-Bodo V, Martelet A, Le Mignon M, Lemoine P, Jain $\mathrm{K}$, et al. Patterns of lgE sensitization in house dust miteallergic patients: implications for allergen immunotherapy. Allergy. 2016;71:220-9. Doi: 10.1111/all.12796.

9. Becker $\mathrm{S}$, Schlederer T, Kramer M, Haack M, Vrtala S, Resch $Y$, et al. Real-Life Study for the Diagnosis of House Dust Mite Allergy - The Value of Recombinant Allergen-Based IgE Serology. Int Arch Allergy Immunol. 2016;170:132-7. Doi: 10.1159/000447694.

10. Huang HJ, Resch-Marat $Y$, Rodriguez-Dominguez A, Chen KW, Kiss $R$, Zieglmayer $P$, et al. Underestimation of house dust 
mite-specific IgE with extract-based ImmunoCAPs compared with molecular ImmunoCAPs, J Allergy Clin Immunol. 2018;142:1656-9. Doi: 10.1016/j.jaci.2018.07.010.

11. Vidal C, Lojo S, Juangorena M, Gonzalez-Quintela A. Association between asthma and sensitization to allergens of Dermatophagoides pteronyssinus. J Investig Allergol Clin Immunol. 2016;26:304-9. Doi: 10.18176/jiaci.0048.

12. Gellrich D, Messmer C, Becker S, Gröger M. Is quantitative serology suitable for distinguishing between silent sensitization and allergic rhinitis to Dermatophagoides pteronyssinus? J Investig Allergol Clin Immunol. 2019;29(2): 124-31. Doi: 10.1876/jiaci.0299.

13. Thomas WR. Hierarchy and molecular properties of house dust mite allergens. Allergol Int. 2015;64:304-11. Doi: 10.1016/j. alit.2015.05.004.

Manuscript received December 6, 2018; accepted for publication March 28, 2019.

Filipa Matos Semedo

Allergy and Immunology Department São Bernardo Hospital, Centro Hospitalar de Setúbal E.P.E.

Rua Camilo Castelo Branco 175 2910-549 Setúbal Portugal

E-mail: pipa.semedo@gmail.com 